\title{
Pharmacogenetics in Europe: Barriers and Opportunities
}

\author{
D. Gurwitz E. Zika M.M. Hopkins S. Gaisser D. Ibarreta \\ European Commission Joint Research Center, Institute for Prospective Technological Studies, Seville, Spain
}

\author{
Key Words \\ Adverse drug reaction - Cost-effectiveness - Diagnostics • \\ Personalized medicine $\cdot$ Policy
}

\begin{abstract}
This paper reviews the current situation in the field of pharmacogenetics/pharmacogenomics (PGX) in Europe. High expectations surrounding the clinical application of PGx remain largely unmet, as only a limited number of such applications have actually reached the market and clinical practice. Thus, the potential impact of PGx-based diagnostics on healthcare and its socio-economic implications are still unclear. With the aim of shedding some light on these uncertainties, the Institute for Prospective Technological Studies (IPTS) of the European Commission's Joint Research Centre (JRC) has conducted a review of the 'state of the art' and a further analysis on the use of pharmacogenetics diagnostics for preventing toxic drug reactions and improving drug efficacy in Europe. The paper presents highlights from the JRC-IPTS studies and discusses possibilities for improving translation of PGx research in Europe by comparing some experiences in the USA. We also illustrate the related barriers for the clinical uptake of PGx in Europe with specific casestudies. Most of the barriers identified extend beyond the European context. This reflects the global problems of scarcity of data demonstrating proven clinical validity or utility and favorable cost-effectiveness studies to support the clinical application of PGx diagnostic tests in the clinical setting. Another key barrier is the lack of incentives for the private
\end{abstract}

sector to invest in the development and licensing of PGx diagnostic tests for improving the safety and efficacy of outof-patent drugs. It therefore seems that one key aspect where policy can affect the clinical uptake of PGx is via sustaining large-scale industry-academia collaborations for developing and proving the utility of PGx diagnostics.

Copyright $\odot 2009$ S. Karger AG, Basel

It is often said that advances in pharmacogenetics and pharmacogenomics (PGx) could positively impact the pharmaceutical and healthcare sectors facilitating drug development and marketing (i.e., better understanding of disease mechanisms, improved drug discovery, improved drug safety and efficacy) [1-6]. PGx is seen as a key element of a system of personalized medical care where genetic records of individuals (which remain unchanged throughout life) along with their medical information records become an integral part of personal electronic health records (EHR), and PGx is used by physicians in taking treatment decisions, with respect to drug and dosage choices [7-10]. However, the high expectations surrounding the clinical application of PGx remain largely unmet, and only a limited number of applications have actually reached the market and clinical practice [11]. Thus, its potential impact on healthcare and its socioeconomic implications remain uncertain.

On the other hand, PGx is an important field of interest in the European scientific community. In 2005, Europe had more PGx public research groups than the US

\section{KARGER \\ Fax +4161306 1234 \\ E-Mail karger@karger.ch}

www.karger.com
(C) 2009 S. Karger AG, Basel

$1662-4246 / 09 / 0123-0134 \$ 26.00 / 0$

Accessible online at:

www.karger.com/phg
Dolores Ibarreta

European Commission Joint Research Center

Institute for Prospective Technological Studies

$\mathrm{C} /$ Inca Garcilaso, Seville (Spain)

Tel. +34 954488 445, Fax +34954 488 434, E-Mail dolores.ibarreta@ec.europa.eu 
Table 1. Challenges and measures in PGx development

\begin{tabular}{|c|c|}
\hline Challenge & Way forward \\
\hline No specific funding & $\begin{array}{l}\text { A current research program of the European Commission } \\
\text { (FP7) includes specific issues in PGx, but more could be done } \\
\text { (e.g., more explicit and better defined allocation) }\end{array}$ \\
\hline Lack of academia-industry collaboration & $\begin{array}{l}\text { Creation of European networks following the success of the } \\
\text { US and Japan (e.g., Innovative Medicines Initiative (IMI) - } \\
\text { promoted by public funding) }\end{array}$ \\
\hline Sharing samples and data & $\begin{array}{l}\text { Promoting and facilitation of networking between biobanks } \\
\text { (e.g., BBMRI initiative, P3G, see text) }\end{array}$ \\
\hline Complexity and interdisciplinarity & Better training programs \\
\hline Intellectual property rights (IPR) issues & $\begin{array}{l}\text { Analysis of IPR issues is an ongoing EU project [17]; a range } \\
\text { of measures to ease licensing concerns require policy support }\end{array}$ \\
\hline $\begin{array}{l}\text { PGx for generic drugs is not financially } \\
\text { attractive }\end{array}$ & Public funding of clinical trials \\
\hline $\begin{array}{l}\text { Low clinical implementation because some } \\
\text { health professionals are unfamiliar with PGx }\end{array}$ & Training programs and continuing education of medical staff \\
\hline Lack of cost-effectiveness studies & $\begin{array}{l}\text { Promoting these studies in research programs, modeling } \\
\text { studies, and data and tool sharing between countries }\end{array}$ \\
\hline $\begin{array}{l}\text { Unclear regulatory framework (drug/test } \\
\text { dichotomy) }\end{array}$ & $\begin{array}{l}\text { European Medicines Agency (EMEA) is providing guidance } \\
\text { and working closely with industry to prevent any ambiguities }\end{array}$ \\
\hline
\end{tabular}

and Japan, although the European groups were smaller in staff numbers. In the private sector there is still a clear US industrial leadership in terms of dedicated small and medium sized enterprises [12].

With the aim of improving knowledge about barriers for PGx implementation in clinical care in the EU, the Institute for Prospective Technological Studies (IPTS) of the European Commission's Joint Research Centre (JRC) has conducted a review of the 'state of the art' and a further analysis on the use of pharmacogenetics diagnostics for improving efficacy and preventing toxic drug reactions in Europe [13-15].

\section{Challenges and Ways Forward}

Hurdles have been identified that affect all steps in the development and clinical uptake of PGx applications [12, 16]. Challenges such as a lack of funding, extending collaboration among industry and academia, achieving clinical studies, and establishing a clear and comprehensive regulatory framework are partly addressed by measures in Europe, as summarized in table 1. These are discussed in more detail in the following sections.

Pharmacogenetics in Europe: Barriers and Opportunities

\section{Improving the Research Base and 'Translation' of}

Research Findings into Practice

A high proportion of public sector research in Europe is financed through core funding from governments [17]. Industrial contracts and funds from charitable foundations play a relatively minor role and contribute mainly to individual projects. Opportunities for industry to access funding from the EU Sixth Framework Programme (FP6; 2002-2006, http://ec.europa.eu/research/fp6/index _en.cfm) have been marred by participant criticism of the high administrative burden and unclear requirements. Academic research in the EU could benefit from greater unification of efforts, better collaboration with the private sector, and funding of more infrastructural support for research. Nearly $40 \%$ of the research groups interviewed complained about the lack of specific research programs to support PGx [18].

A comparison of research budgets in Europe and the USA revealed that US research groups have on average twice the financial resources available to European groups. Several interviewees explained this difference by the investments of the NIH Pharmacogenetics Research Network initiative [19] with an annual budget of USD 25 million.

Public Health Genomics 2009;12:134-141 
Although many applications of pharmacogenetics are still in the research and development phase, future impacts on drug development and healthcare are widely anticipated. The findings of the authors' research and the current focus of European Commission's current Research Framework Programme (FP7, 2007-2013, http:// cordis.europa.eu/fp7/home_en.html) on translational research suggest that attention is required in order to ensure that the potential of pharmacogenetics is fully harnessed in Europe. The FP7 has included pharmacogenetic aspects in many of the project lines in the health area. The overall objective of the health research program is to improve the health of European citizens and increase and strengthen the competitiveness and innovative capacity of European health-related industries and businesses. Emphasis has been put on translational research (i.e., the translation of basic discoveries into clinical applications), the development and validation of new therapies, methods for health promotion and prevention including the promotion of healthy aging, diagnostic tools and medical technologies, and sustainable and efficient healthcare systems (http://ec.europa.eu/research/fp7/index_ en.cfm?pg=health).

Another key barrier is the lack of strong links between academic researchers and private endeavors. This could be improved by policy incentives to enhance collaboration between academia and industry. In general, the private sector values collaboration with the public sector, though the size of research projects that can be subcontracted to academia is often rather small according to expert interviews with industry. Additionally, experts report that, due to strategic and confidentiality reasons related to intellectual property rights (IPR), only a small proportion of tasks can be subcontracted to the public sector. Experts from academia see the different interests in research and IPR issues as being significant obstacles for the extension of industry collaborations [18].

Another difference is the scale of research. Despite targeted long-term projects, such as the Human Genome and the HapMap Project, academia more typically is only able to tackle small scale genomic and PGx projects, whereas industrial drug development processes and, increasingly, diagnostics development require large integrated projects which can capture the genomic and proteomic complexity of large patient cohorts. This may represent another reason for the relatively lower participation rates of public research groups in industrial collaborations in the field.

A potentially beneficial coordination effort would be the creation of networks to promote and sustain collabo- rations between research groups across Europe. In the USA and Japan, the establishment of consortia forms another pillar for networking activities and knowledge transfer. The Japan Pharmacogenomics Consortium (started in 2003) and the NIH Pharmacogenetics Research Network (set in 2000) provided a push for technology transfer in PGx. The EU could benefit from the creation of similar consortia.

In Europe, the industry-academia collaboration might also be better promoted through appropriate European funding programs. A frequent request amongst the interviewees was for the European Commission (EC) research programs to tackle this problem. The basic agreement is that it is not a matter of more funding but of more coordinated funding. One promising example that coordinated industry-academia funding is possible, is the recently launched Innovative Medicines Initiative (IMI) (http:// www.imi-europe.org) [20], which is a unique partnership between the European Community and the European Federation of Pharmaceutical Industries and Associations (EFPIA). It is expected that over the next 5 years IMI will fund research in Europe on the scale of EUR 295 million, with $58 \%$ of this funding being contributed by EFPIA and the rest by the European Commission. These figures may seem small by comparison with the FP7 funding levels, yet they represent a major step forward for industry-academia collaborations in Europe. Although pharmacogenetics is not targeted among the 18 themes of the April 2008 IMI call (http://imi-europa.eu/call-01_ en.html), it is expected that pharmacogenetics applications would play a role in some IMI-funded research projects for new drug development and improved pharmacovigilance in Europe.

\section{Sharing Samples and Data Sets: Infrastructure, \\ Standards, and Legal Framework}

Another possible barrier for realizing the full potential of PGx relates to biobanking and the lack of availability of DNA and tissue samples from well-characterized patients including, with respect to their drug response, phenotypes. Biobanks in Europe have a great potential for medical research including the facilitation of PGx research. However, difficulties for networking and sharing of their samples, in part reflecting lack of harmonization of legal and ethical guidelines across European member states, hinder turning this potential into reality [21]. Against this background, an often mentioned obstacle is the high complexity of data protection requirements: researchers report a mounting bureaucratic burden associated with clinical trials undertaken in the EU, as well as 
increasing difficulty in meeting ethical and regulatory requirements. It has been noted that the proliferation of protective measures and the dynamic nature of policies and guidelines at national levels create challenging conditions for firms operating in the EU.

One main problem in uniting biobanking activities are the existing differences in the handling of personal data, which are at least partly attributed to the varied interpretation and implementation of European Commission directives covering biobanking by member states authorities. One of the main complications is that, although the data protection field is, in theory, harmonized through the EC directive on data protection [22], the collection, storage, and sharing of samples is not standardized. At the same time, actual procedures related to biobanking (e.g., informed consent, future use of samples, sample withdrawal, etc.) are not fully harmonized in the EU, which may pose difficulties for collaborative research. Thus, a key problem remains concerning ensuring the availability of data on different patient populations for undertaking drug efficacy and safety studies as well as the harmonization of legal and regulatory frameworks and ethical committee standards that oversee these processes across Europe. Such harmonization would be essential for the success of biobank networking initiatives particularly as regards sustaining PGx research and diagnostic tests development.

A key development in this direction was the recent funding of the preparatory phase for a pan-European network of existing and de-novo biobanks and biomolecular resources (BBMRI) (www.eurobiobank.eu) by the European Strategy Forum on Research Infrastructure (ESFRI). The network will include biological samples and phenotypic data sets from patients and healthy persons, molecular genomic resources, and bioinformatics tools to optimally exploit this resource for global biomedical research. It is hoped that the BBMRI initiative should facilitate translational research in personalized medicine. Ideally, the private sector should collaborate with this initiative by sharing data sets from concluded clinical trials [23]. Another relevant initiative is the Public Population Project in Genomics (P3G) (http://www.p3gconsortium. org), which is dedicated to fostering collaboration between researchers and projects in the field of population genomics by developing research tools for effective collaboration between biobanks.

In the context of data availability it has been suggested that the clinical implementation of pharmacogenetics may to a large extent depend upon successful integration of EHR into healthcare systems [24].

Pharmacogenetics in Europe: Barriers and Opportunities
Having EHR in place would also go a long way towards reducing costs and thereby improving the cost-effectiveness of PGx, as the human germline genome (unlike tumor genomes) is stable over an individual's lifetime, and therefore, results from a single diagnostic test - if stored in appropriate EHR systems that can be accessible to healthcare providers even when the individual has relocated to another country - would be useful over his/her entire life. Although these systems may offer long-term benefits, at present they pose substantial organizational challenges and are associated with massive costs and therefore remain controversial [25].

\section{Technical and Human Resources}

Further barriers identified in the JRC-IPTS 2006 report [13] include the lack of PGx knowledge among healthcare providers. This aspect includes the scarcity of well-trained human resources in particular in the field of bioinformatics and biostatistics. Lack of education and training for healthcare professionals appears to be a strong barrier for implementation [26]. There is little formal training or guidance for doctors and other medical staff on how to interpret PGx test results and only informal mechanisms to ensure they understand the interpretation sufficiently. Facilitating the clinical uptake of PGx must therefore include relevant education and continued medical training programs for medical professionals involved in PGx (e.g., physicians and nurses) [27, 28].

Technical barriers also include the high level of complexity for PGx studies (DNA sampling, data management, clinical studies, etc.) and high costs of genotyping, although the latter are decreasing, with several private providers recently offering whole-genome scans ( 500,000 SNPs) for under USD 1,000 using chip-based technologies $[29,30]$. Another clear but often overlooked technical barrier are the poor definitions of drug response phenotypes for most common drugs. In many cases, fuzzy medical terms are used for describing poor drug response or adverse drug reactions. Overcoming this barrier would necessitate introduction of harmonized medical terms for describing drug response phenotypes so that large electronic data sets from many clinical trials or aggregate hospital records from several studies (even when coming from different countries) can be mined in tandem for finding reliable correlates between genotypes and their drug response phenotypes [4, 31]. EHR, as discussed above, can become a fundamental instrument in overcoming difficulties.

Public Health Genomics 2009;12:134-141 
Intellectual Property Rights and Licensing Issues

Surprisingly, patent mapping activity in 2005 shows that only half of the core firms involved in pharmacogenetic test development actually held granted US patents citing pharmacogenetic utilities (although it is not known what the situation is like regarding applications) potentially indicating the lack of incentives to invest in IP (intellectual property) portfolios [13]. Alternatively, the language used in patent claims and the licensing agreements these core firms have signed with public sector organizations may mask the true extent of PGx IP. Similarly unclear is the actual impact of related patenting and licensing practices on the diagnostics industry, and there is still a need for more research on the ultimate consequences for healthcare. Research by IPTS in this field is ongoing at present to establish more fully the role of DNA patents in diagnostics.

This is necessary because patenting may present a significant barrier to pharmacogenomics research and the development of related tests if drug or test developers are required to license numerous patents prior to launching their own product or service $[13,32,33]$. In particular, the process of identifying and negotiating access to IPR associated with DNA sequences with a diverse group of owners is already seen as a major 'nuisance' according to some interviewees of the industry. DNA sequences have been intensively patented since the 1990s. The pace of patent filing has been dramatically reduced since 2000, and there are far fewer patents on DNA sequences in Europe than in the USA. Yet the impact of existing and pending patents remains uncertain in the field of diagnostics [34]. It remains possible that the development of patent thickets (a situation where different owners have overlapping patent rights requiring multiple licenses) could pose a significant barrier, and the emergence of new applications for pharmacogenomics may further complicate the situation $[35,36]$. According to experts [37], the potential loss of sales revenue from the more focused prescribing that PGx may bring, is a major disincentive for drug companies. Companies might therefore use patent rights to block the development of diagnostics. On the other hand, some pharmacogenomic tests offer the potential to reduce the costs of clinical trials by preidentifying patients who might experience adverse drug reactions (ADRs) $[38,39]$. In such cases large pharmaceutical companies may choose to pursue the development of relevant diagnostic tests themselves or turn to the expertise of smaller diagnostic firms. Patents would play a key role in such interactions. A range of possible solutions to potential patents entail from compulsory licensing by individual governments to different forms of patent clearing houses $[36,40]$. Implementation of these measures would depend on strong policy support.

\section{PGx Diagnostics for Generic Drugs}

The role of industry in promoting clinical implementation of testing is also essential but seems limited to where there are lucrative markets. The private sector is interested in PGx mostly as a tool for developing and marketing new medicines, following the successful and profitable example of the trastuzumab (Roche's Herceptin) and the Dako Hercept diagnostic test [41, 42]. However, the private sector is by far less enthusiastic about investing in the development of PGx diagnostics for generic drugs, as current re-imbursement systems are accustomed to supporting a low margin market for diagnostic tests, and there is no single beneficiary (and therefore no study sponsor) amongst the drug producers once a product becomes generic. Nonetheless, generic drugs represent the lion's share of ADRs and their healthcare toll. This was observed in studies from the UK [43] and Germany [44] as well as in comprehensive reports by the Centers for Disease Control (CDC) in the USA $[45,46]$. Yet, the private sector has relatively low incentives to develop PGx diagnostics for generic drugs [47]. Improving the current situation calls for enhanced funding by the public sector towards research and development of PGx diagnostics by industry-academia collaborations (see below).

\section{Cost-Effectiveness Analyses}

In our studies, we have seen that the diffusion of pharmacogenetic testing and introduction into clinical practice is not optimal. A clear economic incentive could be very important in leveling some of the barriers to clinical implementation, but cost-effectiveness analysis is not keeping pace with the field. However, though an increasing number of applications of PGx are described in the scientific literature, their economic implications are less often studied [48]. Conducting complete cost-effectiveness analysis of pharmacogenetic testing presents several difficulties, among which are the lack of prospective randomized control trials that can show the clinical utility of the tests, the general underreporting and lack of description of many ADRs [49], and the fact that cost-effectiveness analysis studies concentrate on cases in which ADRs have a strong effect on survival or quality of life of the patient [50]. IPTS is currently studying how cost-effectiveness of pharmacogenetic testing is being done in Europe and what could be done to promote it. A model 
in 2 case studies in pharmacovigilance (TPMT testing in inflammatory bowl disease and CYP2D6 testing in psychiatry) has been attempted, and while both cases seem to be cost-effective, several problems in data availability and harmonization have been identified. This study will be published soon.

In spite of the limited clinical implementation, an explorative cost-effectiveness analysis included in the published JRC-IPTS study provides strong evidence that some applications studied (HER 2 testing in breast cancer and TPMT testing in childhood leukemia) are cost-effective [51].

\section{Regulatory Issues: Facilitated Test Licensing}

While in vitro diagnostics are regulated by the in vitro diagnostic medical devices (IVD) directive in Europe, there currently seems to be a perceived inconsistency of diagnostics approval and testing guidance $[52,53]$.

Evidence from our studies suggests a general support from industry for greater harmonization in the field, although opinions vary as to when and how this should take place. Regardless of the timing, it seems that an appropriate regulatory framework could adequately address potential fear of liability and use of PGx data issues and thus help promote PGx implementation. To address this necessity, the European Medicines Agency (EMEA) and the US Food and Drug Administration (FDA) have started developing new PGx capabilities related to issuing licenses for the US, EU, and other markets [54, 55]. The development of PGx expertise at both agencies appears to have been primarily spurred by industrial enquiries [56].

There are different approaches between the EU and the US. In the latter, the licensing of therapeutics in combination with a diagnostic test is undertaken jointly by a new FDA Office for Combination Products established in 2002 to address some of the emerging issues by taking the lead in combination product applications. It is unclear whether this difference in regulation might have an impact.

\section{Outlook}

PGx holds promise for safer and more effective pharmacotherapy and enhanced preventive medicine and can facilitate new drug development projects. Yet, many barriers - scientific, regulatory, and health policy-related delay the translation of PGx into clinical practice. These barriers have been the subject of several studies [1-11] and remain far from being resolved. Besides the problems of IPR and lack of cost-effectiveness analysis which we have identified and are looking into, we have seen that the clinical utility of pharmacogenetics (and susceptibility genetic testing in general) is not being assessed in prospective studies, and that is an important factor in clinical uptake.

In the current paper we point out that from the European perspective there are novel barriers related to the limited scope of industry-academia collaborations. These barriers may be surmountable by taking innovative policy changes. Europe boasts a powerful pharmaceutical sector and has the scientific talents for carrying out such large projects.

\section{Disclaimer}

The views presented here are those of the authors and do not necessarily represent those of the European Commission.

\section{References}

1 Evans WE, Relling MV: Moving towards individualized medicine with pharmacogenomics. Nature 2004;429:464-468.

-2 Need AC, Motulsky AG, Goldstein DB: Priorities and standards in pharmacogenetic research. Nat Genet 2005;37:671-681.

-3 Giacomini KM, Krauss RM, Roden DM, Eichelbaum M, Hayden MR, Nakamura Y: When good drugs go bad. Nature 2007;446: 975-977.

Pharmacogenetics in Europe: Barriers and Opportunities
-4 Roden DM, Altman RB, Benowitz NL, Flockhart DA, Giacomini KM, Johnson JA, Krauss RM, McLeod HL, Ratain MJ, Relling MV, Ring HZ, Shuldiner AR, Weinshilboum RM, Weiss ST; Pharmacogenetics Research Network: Pharmacogenomics: challenges and opportunities. Ann Int Med 2006;145:749757.

5 Weinshilboum RM, Wang L: Pharmacogenetics and pharmacogenomics: development, science and translation. Annu Rev Genomics Hum Genet 2006;7:223-245.
- 6 Swen JJ, Huizinga TW, Gelderblom H, de Vries EG, Assendelft WJ, Kirchheiner J, Guchelaar HJ: Translating pharmacogenomics: challenges on the road to the clinic. PLoS Med 2007;4:e209.

7 Abrahams E, Ginsburg GS, Silver M: The Personalized Medicine Coalition: goals and strategies. Am J Pharmacogenomics 2005;5: 345-355.

8 Shabo A: The implications of electronic health record for personalized medicine. Biomed Pap Med Fac Univ Palacky Olomouc Czech Repub 2005;149:251-258. 
-9 Sinha G: Electronic health records help recruit trial participants and track drug safety. J Natl Cancer Inst 2008;100:384-385.

-10 Kush RD, Helton E, Rockhold FW, Hardison $\mathrm{CD}$ : Electronic health records, medical research, and the Tower of Babel. N Engl J Med 2008;358:1738-1740.

11 Gurwitz D, Motulsky AG: 'Drug reactions, enzymes, and biochemical genetics': 50 years later. Pharmacogenomics 2007; 8: 14791484.

-12 Hopkins MM, Ibarreta D, Gaisser S, Enzing CM, Ryan J, Martin PA, Lewis G, Detmar S, van den Akker-van Marle ME, Hedgecoe AM, Nightingale P, Dreiling M, Hartig KJ, Vullings W, Forde T: Putting pharmacogenetics into practice. Nat Biotechnol 2006;24: 403-410.

13 Zika E, Gurwitz D, Ibarreta D: Pharmacogenetics and pharmacogenomics: state-of-theart and potential socio-economic impact in the EU. European Commission DG JRC/ IPTS, Technical Report EUR 22214 EN, 2006 http://www.biotechnologyireland.com/ SITE/UPLOAD/DOCUMENT/pharmaco EU.pdf.

-14 Woelderink A, Ibarreta D, Hopkins MM, Rodriguez-Cerezo E: The current clinical practice of pharmacogenetic testing in $\mathrm{Eu}$ rope: TPMT and HER 2 as case studies. Pharmacogenomics J 2006;6:3-7.

-15 Compagni A, Bartoli S, Buehrlen B, Fattore G, Ibarreta D, de Mesa EG: Avoiding adverse drug reactions by pharmacogenetic testing: a systematic review of the economic evidence in the case of TPMT and AZA-induced side effects. Int $\mathrm{J}$ Technol Assess Health Care 2008;24:294-302.

16 Gaisser S: Modelling the arena - actors and processes in genetic testing development, International Conference: Genomics \& Society: Setting the Agenda, Amsterdam, April 2008.

17 Intellectual Property Rights and Diagnostics: the Implications for Pharmacogenomics. Ongoing project 12/2007-12/2008, contracted by European Commission DG JRC, IPTS; within the ETEPS AISBL framework and carried out by Hopkins MM, SPRU Science and Technology Policy Research, University of Sussex, Brighton, UK; Gaisser S, Fraunhofer Institute Systems and Innovation Research, Karlsruhe, Germany; Enzing C, TNO Centre for Technology and Policy Studies, Delft, The Netherlands; Hogarth S, ISS, University of Nottingham, Nottingham, UK.

18 Gaisser S, Dreiling M, Hartig J, Hopkins M, Ryan J, Ibarreta D: Building effective institutional frameworks to support European pharmacogenetic research: an international empirical analysis. Int J Biotech 2008 (in press).
19 Giacomini KM, Brett CM, Altman RB, Benowitz NL, Dolan ME, Flockhart DA, Johnson JA, Hayes DF, Klein T, Krauss RM, Kroetz DL, McLeod HL, Nguyen AT, Ratain MJ, Relling MV, Reus V, Roden DM, Schaefer CA, Shuldiner AR, Skaar T, Tantisira K, Tyndale RF, Wang L, Weinshilboum RM, Weiss ST, Zineh I; Pharmacogenetics Research Network: The Pharmacogenetics Research Network: from SNP discovery to clinical drug response. Clin Pharmacol Ther 2007; 81:328-345.

20 Hunter AJ: The Innovative Medicines Initiative: a pre-competitive initiative to enhance the biomedical science base of Europe to expedite the development of new medicines for patients. Drug Discov Today 2008;13:371373.

-21 Zika E, Schulte In den Bäumen T, Kaye J, Brand A, Ibarreta D: Sample, data use and protection in biobanking in Europe: legal issues. Pharmacogenomics 2008;9:773-781.

22 Directive 95/46/EC of the European Parliament and of the Council of 24 October 1995 on the protection of individuals with regard to the processing of personal data and on the free movement of such data. http://eur-lex. europa.eu/smartapi/cgi/sga_doc?smartapi!c elexapi!prod!CELEXnumdoc\&lg=en\&num doc $=32004 \mathrm{~L} 0023 \&$ model $=$ guichett.

-23 Gurwitz D, Lunshof JE, Altman RB: A call for the creation of personalized medicine databases. Nat Rev Drug Discov 2006;5:2326.

24 Shabo A: Clinical genomics data standards for pharmacogenetics and pharmacogenomics. Pharmacogenomics 2006;7:247-253.

25 Nicholas Timmins Relapse for IT records system, The Financial Times, http://www. ft.com/cms/s/0/7b9d569e-2db3-11dd-b92a000077b07658.html (accessed December 01, 2008).

26 Gurwitz D, Lunshof JE, Dedoussis G, Flordellis CS, Fuhr U, Kirchheiner J, Licinio J, Llerena A, Manolopoulos VG, Sheffield LJ, Siest G, Torricelli F, Vasiliou V, Wong S: Pharmacogenomics education: International Society of Pharmacogenomics recommendations for medical, pharmaceutical, and health schools deans of education. Pharmacogenomics J 2005;5:221-225.

27 Gurwitz D, Weizman A, Rehavi M: Education: teaching pharmacogenomics to prepare future physicians and researchers for personalized medicine. Trends Pharmacol Sci 2003;24:122-125.

28 Frueh FW, Gurwitz D: From pharmacogenetics to personalized medicine: a vital need for educating health professionals and the community. Pharmacogenomics 2004;5: 571-579.

29 Blow N: Genomics: the personal side of genomics. Nature 2007;449:627-630.

-30 van Ommen GB, Cornel MC: Recreational genomics? Dreams and fears on genetic susceptibility screening. Eur J Hum Genet 2008; 16:403-404.
31 Altman RB: PharmGKB: a logical home for knowledge relating genotype to drug response phenotype. Nat Genet 2007;39:426.

32 Nuffield Council Report: Pharmacogenetics: ethical issues. Nuffield Council on Bioethics, London, 2003.

33 Cho MK, Illangasekare S, Weaver MA, Leonard DG, Merz JF: Effects of patents and licenses on the provision of clinical genetic testing services. J Mol Diagn 2003;5:3-8.

- 34 Hopkins MM, Mahdi S, Patel P, Thomas SM: DNA patenting: the end of an era? Nat Biotechnol 2007;25:185-187.

35 Barton JH: Emerging patent issues in genomic diagnostics. Nat Biotechnol 2006;24: 939-941.

36 Kaye J, Hawkins N, Taylor J: Patents and translational research in genomics. Nat Biotechnol 2007;25:739-741.

37 Eisenberg RS: Will pharmacogenomics alter the role of patents in drug development? Pharmacogenomics 2002;3:571-574.

- 38 Nilsson LJ, Regnström KJ: Pharmacogenomics in the evaluation of efficacy and adverse events during clinical development of vaccines. Methods Mol Biol 2008;448:469-479.

39 Ohashi W, Mizushima H, Tanaka H: Economic advantage of pharmacogenomics clinical trials with genetic information. Stud Health Technol Inform 2008;136:585-590.

40 van Zimmeren E, Verbeure B, Matthijs G, Van Overwalle G: A clearing house for diagnostic testing: the solution to ensure access to and use of patented genetic inventions? Bull World Health Organ 2006;84:352-359.

41 Bartlett JM: Pharmacodiagnostic testing in breast cancer: focus on HER2 and trastuzumab therapy. Am J Pharmacogenomics. 2005;5:303-315.

42 Kroese M, Zimmern RL, Pinder SE: HER2 status in breast cancer - an example of pharmacogenetic testing. J R Soc Med 2007;100: 326-329.

43 Pirmohamed M, James S, Meakin S, Green C, Scott AK, Walley TJ, Farrar K, Park BK, Breckenridge AM: Adverse drug reactions as cause of admission to hospital: prospective analysis of 18,820 patients. BMJ 2004;329: 15-19.

44 Dormann H, Neubert A, Criegee-Rieck M, Egger T, Radespiel-Tröger M, Azaz-Livshits T, Levy M, Brune K, Hahn EG: Readmissions and adverse drug reactions in internal medicine: the economic impact. J Intern Med 2004;255:653-663.

45 Budnitz DS, Pollock DA, Weidenbach KN, Mendelsohn AB, Schroeder TJ, Annest JL: National surveillance of emergency department visits for outpatient adverse drug events. JAMA 2006;296:1858-1866.

-46 Budnitz DS, Shehab N, Kegler SR, Richards CL: Medication use leading to emergency department visits for adverse drug events in older adults. Ann Intern Med 2007;147:755765 . 
47 Lunshof JE, Pirmohamed M, Gurwitz D: Personalized medicine: decades away? Pharmacogenomics 2006; 7:237-241.

48 Phillips KA, van Bebber SL: A systematic review of cost-effectiveness analyses of pharmacogenomic interventions. Pharmacogenomics 2004;5:1139-1149.

49 Hazell L, Shakir SA: Under-reporting of adverse drug reactions: a systematic review. Drug Saf 2006;29:385-396.

-50 Tengs TO: Cost-effectiveness versus costutility analysis of interventions for cancer: does adjusting for health-related quality of life really matter? Value Health 2004;7:7078.
51 van den Akker-van Marle ME, Gurwitz D, Detmar S, Enzing CM, Hopkins MM, Gutierrez de Mesa E, Ibarreta D: Cost-effectiveness of pharmacogenomics in clinical practice: a case study of thiopurine methyltransferase genotyping in acute lymphoblastic leukemia in Europe. Pharmacogenomics 2006;7:783-792.

52 Hogarth S, Liddell K, Ling T, Sanderson S, Zimmern R, Melzer D: Closing the gaps - enhancing the regulation of genetic tests using responsive regulation. Food Drug Law J 2007;62:831-848.

53 Hogarth S, Melzer D: The IVD Directive and Genetic Testing. Problems and proposals. A briefing presented to the 20th meeting of Competent Authorities, Lisbon, July 2007.
54 Goodsaid F, Frueh FW: Implementing the US FDA guidance on pharmacogenomic data submissions. Environ Mol Mutagen 2007;48:354-358.

55 EU (European Commission and EMEA) and FDA Agree on Guiding Principles for Joint FDA EMEA Voluntary Genomic Data Submission Briefing Meetings. FDA press release, May 2006. http://www.fda.gov/bbs/ topics/NEWS/2006/NEW01383.html.

56 Breckenridge A, Lindpaintner K, Lipton P, McLeod H, Rothstein M, Wallace H: Pharmacogenetics: ethical problems and solutions. Nat Rev Genet 2004;5:676-680. 